\title{
МОДЕЛЮВАННЯ ПРОЦЕСУ ГАРЯЧОЇ ПРОКАТКИ ТРИШАРОВИХ ШТАБ ЗІ СПЛАВІВ АЛЮМІНІЮ ТА МАГНІЮ
}

Вироби з магнієвих сплавів мають великі перспективи застосування в аерокосмічній та автомобілебудівній промисловості. Це пов'язано з їх високою питомою міцністю та демпфуючою здатністю, простотою розливки та обробки. Широкому застосуванню сплавів магнію перешкоджає їх низька стійкість до корозії.

Алюміній та його сплави знайшли широке застосування у промисловості. Це пов'язано з їх відносно низькою щільністю, високою корозійною стійкістю та широким різноманіттям властивостей.

Поєднання основних переваг сплавів магнію та алюмінію можливо у їх біметалевих композиціях. Адже алюміній має високу стійкість до корозії, а магній та його сплави мають високі демпфуючі властивості. Це дозволяє використовувати такий багатошаровий матеріал у конструкціях, де наявні вібрації та агресивні середовища.

Найбільш поширеними видами біметалевих матеріалів, які застосовуються в автомобілебудівний та аерокосмічній промисловості $є$ листи та штаби. Прокатка $є$ найбільш простим та продуктивним способом отримання багатошарових металевих композитів. Для листових виробів найбільш зручними у застосуванні $\epsilon$ асиметрична холодна та гаряча прокатка і процес інтенсивної пластичної деформації, який отримав назву «Accumulative Roll Bonding» (ARB) [1]. В процесі ARB матеріали складують пакетом та прокатують з високими ступенями деформації за різну кількість проходів. При цьому після кожного проходу заготовка поділяється навпіл та складується у новий пакет. Ступень деформації в кожному проході досягає 50 \%. Процес ARB застосовують як для з’єднання штаб зі сплавів алюмінію та магнію [2] так і для алюмінієвих сплавів різного хімічного складу $[3,4]$.

Застосування процесу ARB дозволяє одночасно використовувати такі складові механізму керування властивостями біметалевих композицій, як розмір зерна, градієнт властивостей по висоті виробу та зміцнення перехідної зони інтерметалідами. Крім того, як показано в роботі [2], на властивості отриманого композиту впливає термообробка. Ступень деформації штаби та режим наступної термічної обробки формують кінцеві механічні властивості через зміну структури металу та рівня напружень в ньому. В роботі [2] для отримання тришарової штаби зі сплавів алюмінію 5052 та магнію AZ31, застосовували прокатку у два проходи 3 проміжним відпалом. Товщина листів 3 алюмінію складала 0,5 мм, а товщина листа магнію - 2,5 мм. Варіювали часом витримки та температурою відпалу. При цьому ступені деформації по проходам складали 42,9 \% та 35 \% відповідно. Авторами була відмічена залежність товщини зони інтерметалідів на границі алюмінію та магнію, від часу термічної обробки.

У якості фінальної обробки, для отримання біметалевих штаб може застосовуватися холодна прокатка. В роботі [5] було досліджено вплив холодної деформації на мікроструктуру та механічні властивості біметалевих штаб Al-Mg. При цьому прокату вели з високими ступенями деформації, які досягали 50 \%.

Аналіз наукових публікацій показав, що матеріали та параметри процесу прокатки, який застосовується для отримання багатошарових композицій, мають велику різноманітність. При цьому процес здійснюється з високими ступенями деформації за прохід, що досягають 50 \%. Такі деформації обумовлюють високі контактні напруження та енергосилові параметри при прокатці. 3 метою попередньої оцінки навантажень на діюче устаткування при виконанні експериментальних досліджень, доцільно мати математичну модель процесу. 
Метою роботи є створення математичної моделі процесу прокатки тришарових штаб зі сплавів алюмінію та магнію і перевірка іiї працездатності при дослідженні силових параметрів прокатки.

Для теоретичного дослідження параметрів при поздовжній прокатці тришарових штаб зі сплавів $\mathrm{Al}$ та $\mathrm{Mg}$, була створена модель процесу гарячої прокатки у програмному комплекci QForm фірми «КванторФорм». Програма QForm (версія VX8.2) призначена для математичного моделювання методом скінчених елементів процесів обробки металів тиском. Опір деформації матеріалу заготовку вважається залежним від накопленої деформації, поточної швидкості деформації і температури та задається у вихідних даних. Матеріал вважається ізотропним та таким, що ізотропно зміцнюється [6, 7].

У якості матеріалу для моделювання були обрані марки алюмінію AW-2017A (EN573) та магнію AZ31 (ASTM). Ці сплави були обрані з причини своєї поширеності та широкого використання у промисловості. Алюмінієвий сплав AW-2017А використовується для виготовлення напівфабрикатів (листів, стрічок, штаб, плит, профілів, панелей, прутків, труб, дроту, штамповок і поковок) методом гарячої або холодної деформації, а також злитків і слябів. Магнієвий сплав AZ31 - сплав, що має високу міцність, зварюваність, корозійну стійкість. Має у своєму составі вміст алюмінію в межах 2,5-3,5 \%, що має покращити зчеплення між шарами.

Фізичні властивості сплаву AW-2017А, які було задано при моделюванні: щільність

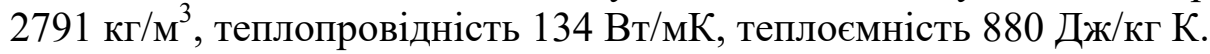

Фізичні властивості сплаву AZ31, які було задано при моделюванні: щільність 1740 кг/м³ , теплопровідність 96 Вт/мК, теплоємність 960 Дж/кг К.

Для опису залежності опору деформації досліджуваних матеріалів від величини температури, швидкості та ступеня деформації, використовували дані, які наведені у науковій літературі $[8,9]$.

Довжина штаби, яку задавали для розрахунку процесу прокатки, складала 200 мм, ширина - 25 мм.

Штаба (пакет) складався з двох зовнішніх шарів алюмінієвого сплаву та з внутрішнього шару магнію. Схема пакету представлена на рис. 1.

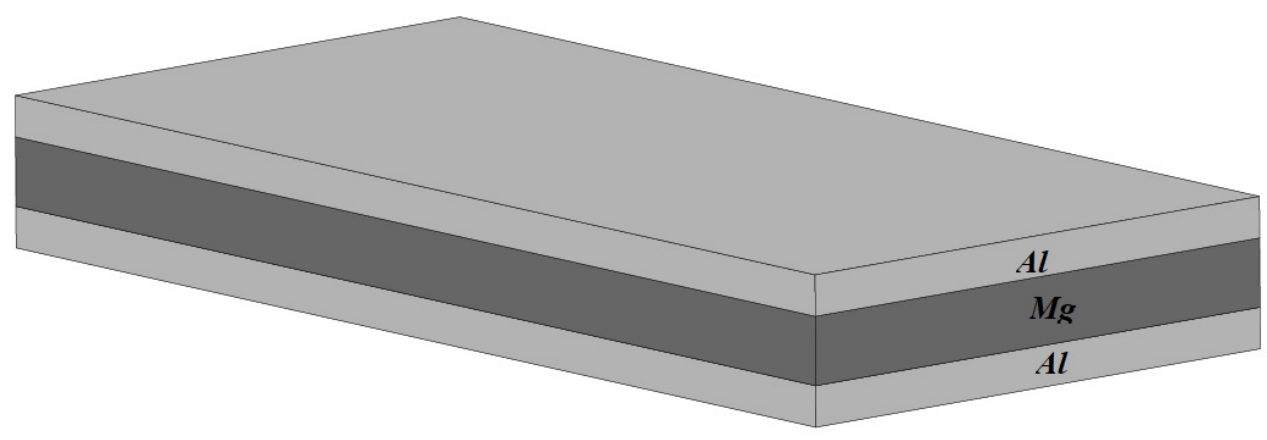

Рис. 1. 3D модель тришарової заготовки Al-Mg-Al

Параметри робочого інструмента (валків) відповідали розмірам валків лабораторного стана дуо 180 кафедри ОМТ НМетАУ. Швидкість обертання валків - 26 об/хв., Матеріал інструменту - сталь 9ХГВ, Початкова температура інструменту - $20{ }^{\circ} \mathrm{C}$, Температура навколишнього середовища $-20{ }^{\circ} \mathrm{C}$.

Додаткові вихідні дані для моделювання: накопичена ступінь деформації - відсутня, коефіцієнт зміни об'єму для кожної заготовки - 1,0, теплообмін з заготовкою - простий, модель тертя між заготовками - повне прилипання, модель тертя між заготовкою та інструментом задавали для умов гарячої прокатки сплавів алюмінію без мастила, яка описується законом О. М. Леванова. Обтиск штаб задавався зазором між робочими валками. 
При моделюванні симетричних процесів, наприклад, процес прокатки штаби на гладкій бочці, у програмі QForm можливо задавати площини симетрії у 3D моделі, та вести розрахунок для половини або чверті моделі. Цій підхід дозволяє значно скоротити час розрахунку. Його було використано для моделювання процесу прокатки тришарової штаби в стані дуо.

На рис. 2 показана графічна модель валків та вихідної заготовки, яку використовували при дослідженні процесу прокатки.

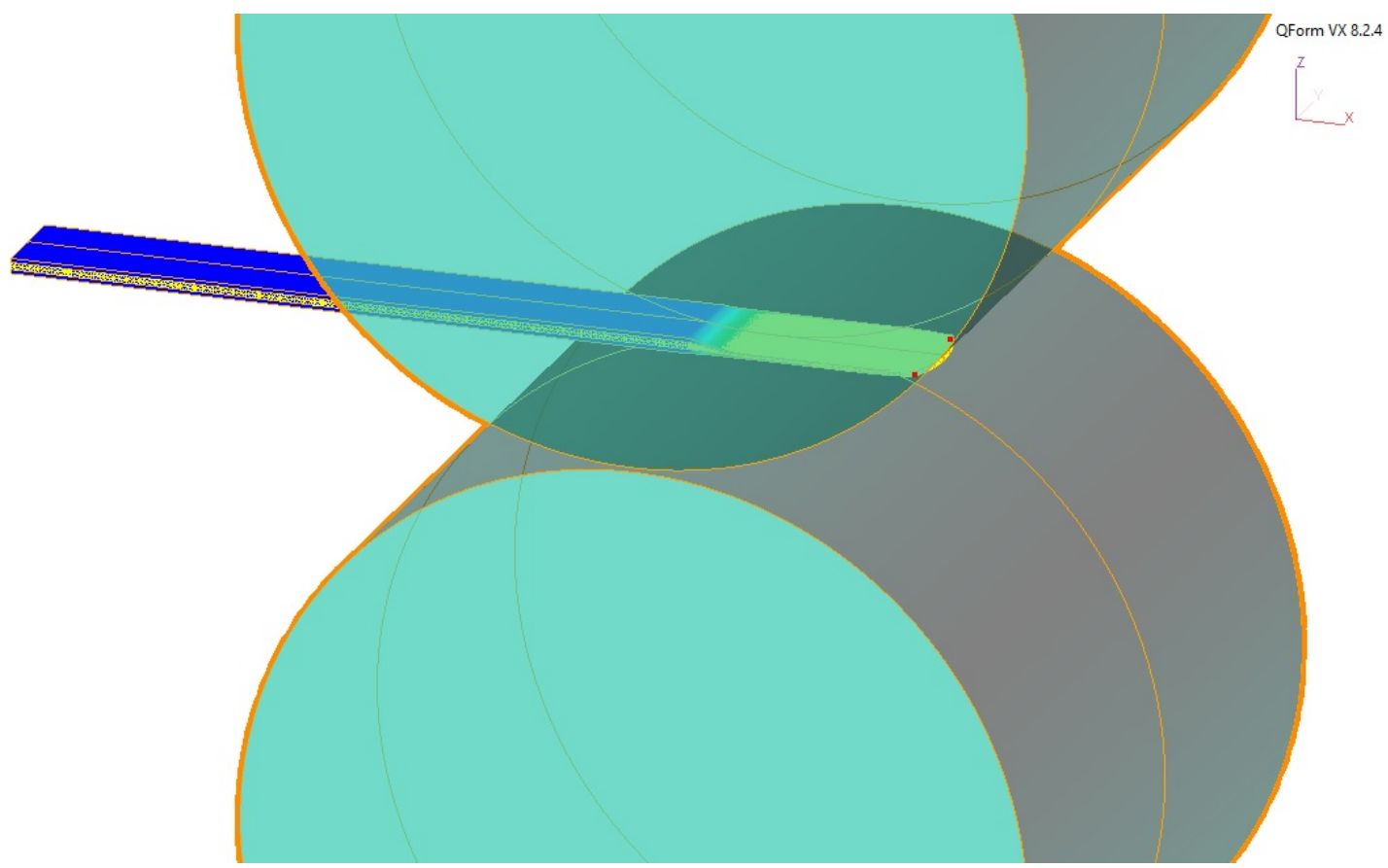
моделюванні

Рис. 2. Графічна модель валків та тришарової штаби, яка використовувалась при

Наявність двох різних заготовок та високе значення фактору форми зони деформації, ускладнює розрахунок методом скінчених елементів. Тому, для моделювання таких випадків прокатки, доцільно використовувати різні граничні умови для адаптації сітки скінчених елементів. Використовували згущення сітки в зоні деформації.

3 використанням моделі процесу прокатки тришарових штаб зі сплавів алюмінію та магнію, було виконано теоретичне дослідження комплексного впливу температури та ступеня деформації на енергосилові параметри та формозміну металу при прокатці. Початкова температура заготовки складала 360 та $410{ }^{\circ} \mathrm{C}$. Початкові та кінцеві розміри штаб, їх обтиски, приведені в табл. 1.

Таблиця 1

Початкові та кінцеві розміри штаб при моделюванні

\begin{tabular}{|c|c|c|c|c|c|c|}
\hline № пакету & Шари & $\begin{array}{l}h_{0}, \\
\text { MM }\end{array}$ & $\begin{array}{c}h_{0 \Sigma}, \\
\mathrm{MM}\end{array}$ & $\begin{array}{l}h_{1}, \\
\text { MM }\end{array}$ & $\begin{array}{l}h_{\Delta} \\
\text { MM }\end{array}$ & $\begin{array}{l}\varepsilon, \\
\%\end{array}$ \\
\hline \multirow{3}{*}{1} & $\mathrm{Al}$ & 1,0 & \multirow{3}{*}{3,8} & \multirow{3}{*}{2,66} & \multirow{3}{*}{1,14} & \multirow{3}{*}{30} \\
\hline & $\mathrm{Mg}$ & 1,8 & & & & \\
\hline & $\mathrm{Al}$ & 1,0 & & & & \\
\hline \multirow{3}{*}{2} & $\mathrm{Al}$ & 1,0 & \multirow{3}{*}{3,8} & \multirow{3}{*}{1,90} & \multirow{3}{*}{1,90} & \multirow{3}{*}{50} \\
\hline & $\mathrm{Mg}$ & 1,8 & & & & \\
\hline & $\mathrm{Al}$ & 1,0 & & & & \\
\hline \multirow{3}{*}{2} & $\mathrm{Al}$ & 1,0 & \multirow{3}{*}{3,8} & \multirow{3}{*}{1,14} & \multirow{3}{*}{2,66} & \multirow{3}{*}{70} \\
\hline & $\mathrm{Mg}$ & 1,8 & & & & \\
\hline & $\mathrm{Al}$ & 1,0 & & & & \\
\hline
\end{tabular}


За даними розрахунку у програмі QForm отримали значення сили при прокатці.

На рис. 3 наведено результати моделювання процесу прокатки біметалевих тришарових штаби з обтисненнями 30, 50 та 70 \% при температурах деформації 360 та $410{ }^{\circ} \mathrm{C}$.

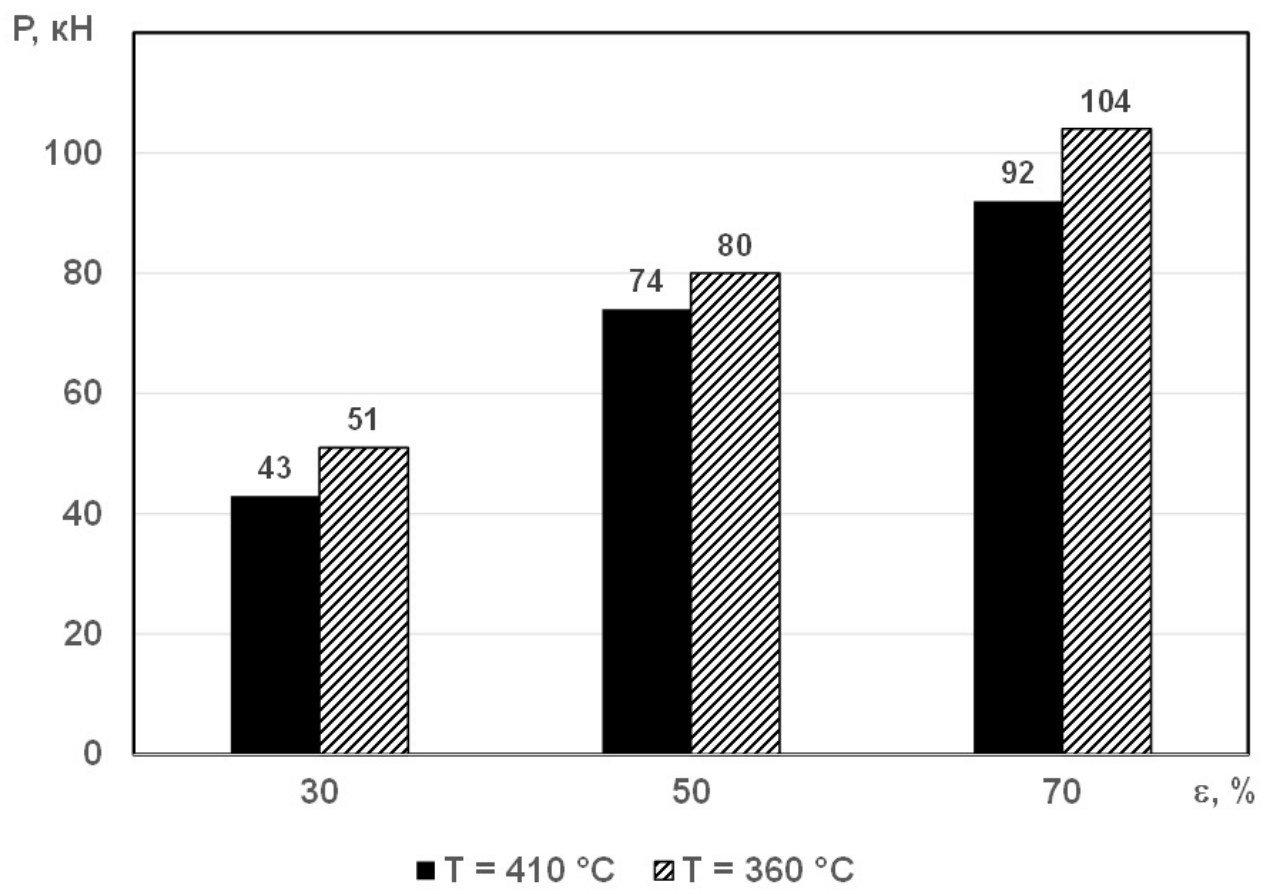

Рис. 3. Величина сили деформації при прокатці тришарових штаб Al-Mg-Al

Як слідує 3 рис. 3, значення сили прокатки для температури початку деформації $360{ }^{\circ} \mathrm{C}$ знаходяться у діапазоні $51-104$ кН, а для випадку процесу при початковій температурі заготовки $410^{\circ} \mathrm{C}-$ у діапазоні 43-92 кН, що є наслідком зниження опору деформації та відповідає існуючим уявленням теорії прокатки. 3 підвищенням ступеня деформації, сила прокатки збільшується.

Експериментальне дослідження впливу процесу прокатки тришарових штаб Al-Mg-Al проводили у лабораторії на кафедрі обробки металів тиском НМетАУ. Для їх виконання використовувався лабораторний прокатний стан Дуо 180 з гладкою бочкою валків. Прокатка здійснювалася серіями по три зразки. Швидкість обертання валків складала 0,26 м/с.

Перед складенням алюмінієвих та магнієвих штаб в пакет, їх поверхні були знежирені. Вихідні розміри пакетів (довжина, ширина, товщина) відповідали значенням, наведеним у табл. 1. Співвідношення товщин шарів сплавів алюмінію та магнії складало відповідно $1: 1,8: 1$.

Для нагріву заготовок використовували камерну електричну піч 3 діапазоном нагрівання 50-800 ${ }^{\circ} \mathrm{C}$, яка розташовувалась безпосередньо біля прокатного стана. Для вимірювання температури застосовували термопари та пристрій USB TC-08 фірми Pico Technology, за допомогою якого можливо фіксація температури одночасно з декількох термопар. Пакети нагрівали до температури 370 та $420^{\circ} \mathrm{C}$. Час нагрівання зразків складав близько 4-5 хвилин. На столі прокатної кліті був розташований теплоізолюючий матеріал для запобігання теплообміну між пакетом штаб та столом. Температура металу контролювалася термопарою, яка знаходилася у шарі магнію.

Для визначення сили прокатки використовувалися силовимірювальні пристрої - месдози, які були встановлені під натискні гвинти прокатної кліті.

Після прокатки вимірювали товщину, ширину и довжину зразків. За результатами вимірювань розраховували абсолютний обтиск $\Delta h$, ступінь деформації $\varepsilon$ та коефіцієнт витяжки $\lambda$. Коефіцієнт витяжки розраховували як відношення початкової та кінцевої площі поперечного перерізу. Зображення прокатаних композитів представлено на рис. 4. 


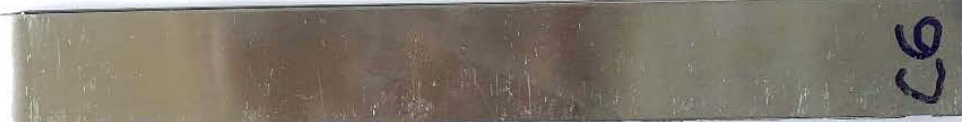

Рис. 4. Тришарові композити зі сплавів AW-2017A та AZ31 до прокатки (коротший) та після прокатки

Результати експериментальних досліджень сили прокатки наведено у таблиці 2.

Таблиця 2

Результат експериментальних досліджень процесу прокатки тришарових штаб Al-Mg-Al

\begin{tabular}{|c|c|c|c|c|c|c|c|}
\hline № cepiï & $\begin{array}{c}\mathrm{t},{ }^{\circ} \mathrm{C} \\
\text { нагріву }\end{array}$ & $\begin{array}{l}\mathrm{t},{ }^{\circ} \mathrm{C} \\
\text { входу }\end{array}$ & $\begin{array}{l}\mathrm{h}_{0} \\
\mathrm{MM}\end{array}$ & $\begin{array}{c}\mathrm{h}_{1} \\
\text { (середня)мм }\end{array}$ & $\begin{array}{l}\mathrm{h}_{\Delta} \\
\mathrm{MM}\end{array}$ & $\varepsilon \%$ & Р кН \\
\hline 1 & 370 & 352 & 3,8 & 2,60 & 1,20 & 31,6 & 54 \\
\hline 2 & 420 & 410 & 3,8 & 2,55 & 1,25 & 32,9 & 47 \\
\hline 3 & 370 & 358 & 3,8 & 1,80 & 2,00 & 52,6 & 89 \\
\hline 4 & 420 & 408 & 3,8 & 1,80 & 2,00 & 52,6 & 83 \\
\hline
\end{tabular}

Аналіз даних таблиці 2 свідчить про те, що величини сили прокатки, які отримані при моделюванні, близько відповідають величинам сили, що отримані при проведенні експериментальних досліджень. Для всіх випадків процесу, значення сили прокатки, які отримані з експериментальних даних, декілька вище розрахункових. Наприклад: при прокатці з ступенем деформації 52,6\% при температурі початку деформації $360{ }^{\circ} \mathrm{C}$, експериментальне значення сили прокатки склало $89 \mathrm{\kappa H}$, а при моделюванні в програмному комплексі QForm 80 кН. Для випадку прокатки зі ступенем деформації 52,6 \% при температурі початку деформації $410^{\circ} \mathrm{C}$, експериментальне значення сили прокатки склало $83 \mathrm{\kappa H}$, а при моделюванні в програмному комплексі QForm - 74 кН. Тобто різниця між розрахунковими та експериментальними значеннями сили прокатки складає 10,1-10,8 \%.

Для прокатки зі ступенем деформації 30 \% спостерігається так сама картина: при температурі початку деформації $360^{\circ} \mathrm{C}$, експериментальне значення сили прокатки склало 54 кН, а при моделюванні в QForm - 51 кН. Для температури початку деформації $410^{\circ} \mathrm{C}$, експериментальне значення сили прокатки склало 47 кH а при моделюванні в програмі QForm - 43 кH. Тобто різниця між розрахунковими та експериментальними значеннями сили прокатки складає 5,6-8,5\%.

Прокатку зі ступенями деформації 70 \% не проводили, так як розрахункове значення сили прокатки для такого ступеня деформації перевищувало 100 кН, що є граничним значення для месдоз, які використовували в експериментальних дослідженнях. Крім того, можуть виникати труднощі з захопленням штаби валками при великих ступенях деформації.

Експериментальне дослідження показало, що при прокатці зразків зі ступенем деформації $50 \%$, зчеплення шарів в пакеті відбулось як при температурі деформації $360{ }^{\circ} \mathrm{C}$ так і $410{ }^{\circ} \mathrm{C}$. Проте при прокатці зразків зі ступенем деформації 30 \%, надійного зчеплення шарів не спостерігалось.

3 точки зору температури деформації, температура початку прокатки $410{ }^{\circ} \mathrm{C} є$ більш привабливою, оскільки при більш низьких температурах та при великих ступенях деформації, спостерігалося розтріскування шару магнію на бокових кромках тришарової штаби (рис. 5). 


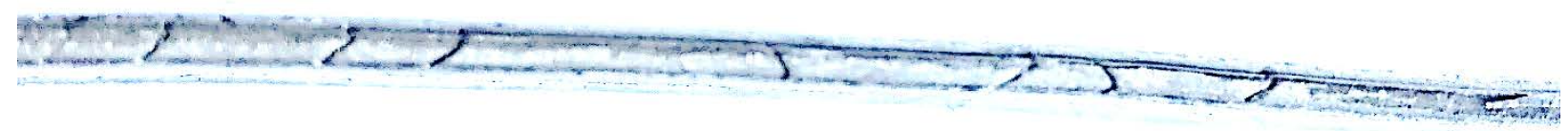

Рис. 5. Тріщини на боковій поверхні шару зі сплаву магнію AZ31

Як видно з рис. 5, при температурі початку деформації $360{ }^{\circ} \mathrm{C}$, у шарі магнію спостерігаються тріщини, що розташовані під кутом $45^{\circ}$. Можливо це пов'язано зі швидким охолодженням кромок штаби при прокатці. Розподіл температури по шарам тришарової штаби у процесі гарячої деформації потребує додаткових досліджень. Доцільно провести аналіз процесу прокатки тришарових штаб у програмному комплексі QForm з використанням критерію Кокрофта - Латама, або іншого критерію, для оцінки можливості руйнування шарів магнію в процесі гарячої деформації.

\section{ВИСНОВКИ}

Розроблена модель процесу прокатки тришарових штаб зі сплавів алюмінію та магнію у програмі QForm. Виконане теоретичне дослідження впливу ступеня деформації та температури на силу прокатки.

Виконано експериментальне дослідження процесу прокатки тришарових штаб зі сплавів AW-2017A та AZ31 зі ступенями деформації 30 та 50 \%. Дослідження показало, що використання поверхневих шарів алюмінію дозволяє отримати велику деформацію магнієвого сплаву, яку складно досягти при прокатці монометалічних штаб з магнію. Було встановлено, що при прокатці зі ступенем деформації 50 \%, відбувається надійне зчеплення шарів алюмінію та магнію. Для випадку прокатки зі ступенем деформації 30 \% зчеплення шарів відбувається не завжди.

Співставлення розрахункових, отриманих з використанням математичної моделі, та експериментальних значень сили прокатки показало, що вони добре співпадають. Розбіжність між експериментальними та теоретичними значеннями сили складає від $+5,6$ \% до 10,8 \%.

\section{СПИСОК ВИКОРИСТАНОЇ ЛІТЕРАТУРИ}

1. Saito Y., Tsuji N., Utsunomiya H., Sakai T., Hong R.G. Ultra-fine grained bulk aluminum produced by accumulative roll-bonding (ARB) process. Scripta. Materialia. 1998. 39, pp. 1221-1227.

DOI: https://doi.org/10.1016/S1359-6462(98)00302-9

2. Changzeng Luo, Wei Liang, Zhiqiang Chen, Jianjun Zhang, Chengzhong Chi, Fuqian Yang. Effect of high temperature annealing and subsequent hot rolling on microstructural evolution at the bond-interface of $\mathrm{Al} / \mathrm{Mg} / \mathrm{Al}$ alloy laminated composites. Materials characterization. 2013. 84, pp. 34-40.

DOI: https://doi.org/10.1016/j.matchar.2013.07.007

3. Goken M., Hoppel H.W. Tailoring nanostructured, graded, and particle-reinforced Al laminates by accumulative roll bonding. Advanced Materials. 2011. 23, pp. 2663-2668. DOI: https://doi.org/10.1002/adma.201100407

4. Shibayan Roy, Nataraj B.R., Satyam Suwas, Kumar S., Chattopadhyay K. Accumulative roll bonding of aluminum alloys 2219/5086 laminates: Microstructural evolution and tensile properties. Materials \& Design (19802015), 2012. 36, pp. 529-539. DOI: https://doi.org/10.1016/j.matdes.2011.11.015

5. Changa H., Zheng M.Y., Xub C., Fanb G.D., Brokmeier H.G., Wu K. Microstructure and mechanical properties of the $\mathrm{Mg} / \mathrm{Al}$ multilayer fabricated by accumulative roll bonding (ARB) at ambient temperature. Materials Science and Engineering: A. 2012. 543, pp. 249-256. DOI: https://doi.org/10.1016/j.msea.2012.02.083

6. New version of QForm VX has been released. 2017. URL: http://qform3d.com/news/2017/05/17

7. QForm - Software for simulation and optimization of metal forming processes and metal profile extrusion, QFX Simulations Ltd. URL: http://www.qform3d.com/

8. Полухин П. И., Гун Г. Я., Галкин А. М. Сопротивление пластической деформации металлов и сплавов. Москва: Машиностроение, 1983. 352 с.

9 L. De Pari Jr., Misiolek W.Z., Forsmark J.H., Luo A.A. Flow stress numerical modeling for large strain deformation in magnesium. Computer Methods in Materials Science. 2010. 10. 2, pp. 108-129.

URL: http://www.cmms.agh.edu.pl/abstract.php?p id=280 


\section{REFERENCES}

1. Saito Y., Tsuji N., Utsunomiya H., Sakai T., Hong R.G. Ultra-fine grained bulk aluminum produced by accumulative roll-bonding (ARB) process. Scripta. Materialia. 1998. 39, pp. 1221-1227.

DOI: https://doi.org/10.1016/S1359-6462(98)00302-9

2. Changzeng Luo, Wei Liang, Zhiqiang Chen, Jianjun Zhang, Chengzhong Chi, Fuqian Yang. Effect of high temperature annealing and subsequent hot rolling on microstructural evolution at the bond-interface of $\mathrm{Al} / \mathrm{Mg} / \mathrm{Al}$ alloy laminated composites. Materials characterization. 2013. 84, pp. 34-40.

DOI: https://doi.org/10.1016/j.matchar.2013.07.007

3. Goken M., Hoppel H.W. Tailoring nanostructured, graded, and particle-reinforced Al laminates by accumulative roll bonding. Advanced Materials. 2011. 23, pp. 2663-2668. DOI: https://doi.org/10.1002/adma.201100407

4. Shibayan Roy, Nataraj B.R., Satyam Suwas, Kumar S., Chattopadhyay K. Accumulative roll bonding of aluminum alloys 2219/5086 laminates: Microstructural evolution and tensile properties. Materials \& Design (19802015), 2012. 36, pp. 529-539.DOI: https://doi.org/10.1016/j.matdes.2011.11.015

5. Changa H., Zheng M.Y., Xub C., Fanb G.D., Brokmeier H.G., Wu K. Microstructure and mechanical properties of the $\mathrm{Mg} / \mathrm{Al}$ multilayer fabricated by accumulative roll bonding (ARB) at ambient temperature. Materials Science and Engineering: A. 2012. 543, pp. 249-256. DOI: https://doi.org/10.1016/j.msea.2012.02.083

6. New version of QForm VX has been released. 2017. URL: http://qform3d.com/news/2017/05/17

7. QForm - Software for simulation and optimization of metal forming processes and metal profile extrusion, QFX Simulations Ltd. URL: http://www.qform3d.com/

8. Poluchin P.I., Gun G.Y., Galkin A.M. Resistance to plastic deformation of metals and alloys. Moscow: Mechanical Engineering. 1983. 352 p. (in Russian).

9. L. De Pari Jr., Misiolek W.Z., Forsmark J.H., Luo A.A. Flow stress numerical modeling for large strain deformation in magnesium. Computer Methods in Materials Science. 2010. 10. 2, pp. 108-129.

URL: http://www.cmms.agh.edu.pl/abstract.php?p id=280

Коноводов Д. В. - канд. техн. наук, доц., доцент кафедри ОМТ НМетАУ; E-mail: konovodov@metal-forming.org

Сиваш В. I. $\quad$ - аспірант кафедри ОМТ НМетАУ; E-mail: sivashvasiliy@gmail.com

НМетАУ - Національна металургійна академія України, м. Дніпро. 